\title{
A IMPORTÂNCIA DA ERGONOMIA DO AMBIENTE CONSTRUÍDO NOS PROJETOS ARQUITETÔNICOS - O CASO DOS DEFICIENTES AUDITIVOS
}

\author{
NEVES, Renata de Assunção (1); \\ NEVES, Aline da Silva Oliveira (2) \\ (1) Universidade Federal de Pernambuco, Graduanda em Arquitetura e \\ Urbanismo e-mail:renatanevesdesign@gmail.com \\ (2) Universidade Federal de Pernambuco, Doutoranda em \\ Design e-mail:linebelar@gmail.com
}

\begin{abstract}
RESUMO
No desenvolvimento projetual, o arquiteto deve planejar o espaço de forma que abranja tanto 0 conforto físico quanto o psicológico, levando em consideração as premissas do desenho universal. A intervenção ergonômica sofre algumas limitações devido ao processo projetual falho, demandando um custo maior para adaptação do espaço em casos específicos. Este estudo pretende demonstrar a importância do uso desenho universal como diretriz de projeto, especificar as restrições sofridas por pessoas com deficiência auditiva que impedem ou dificultam o processo de interação social e cognitivo e demonstrar como soluções projetuais podem trazer resoluções para estes problemas.
\end{abstract}

Palavras chave: ergonomia; design universal; deficiência auditiva.

\begin{abstract}
In design development, the architect must plan space in a way that encompasses both physical and psychological comfort, taking into account the premises of universal design. The ergonomic intervention suffers some limitations due to the flawed design process, requiring a greater cost to adapt the space in specific cases. This study aims to demonstrate the importance of using universal design as a design guideline, to specify the restrictions experienced by people with hearing impairment that impede or hamper the process of social and cognitive interaction and to demonstrate how design solutions can bring resolutions to these problems.
\end{abstract}

Keywords: human factors; universal design; hearing deficiency

\section{INTRODUÇÃO}

De acordo com o Censo Demográfico, no Brasil existem cerca de 45 milhões de pessoas com algum tipo de deficiência, equivalendo a $23,92 \%$ da população brasileira. Dentro desse contexto entende-se que o ambiente construído deve ser pensado de forma acessível e inclusiva para qualquer perfil de usuário, incluindo além desta parcela da população, idosos, pessoas com mobilidade reduzida temporária, gestantes, crianças, entre outros.

Pode-se dizer que a arquitetura pensada em um "homem-padrão" é falha e não funcional, visto que não consegue abarcar as diversas situações não englobadas no "homem médio", além de ser uma arquitetura exclusiva e agressiva em alguns aspectos. 


\section{(x) $^{\text {remax }}$}

Além disso, o uso do espaço pode ocorrer de forma consciente ou inconsciente, influenciando estados de humor e apropriações sociais. Por isso, a importância da percepção ambiental deve caminhar de forma paralela aos aspectos de confortos térmico, acústico e lumínico, além da distribuição e estrutura física do local e aspectos de acessibilidade. Villarouco expõe que

a adaptabilidade ergonômica do espaço, inclui atendimento aos anseios do usuário, não apenas nos aspectos referentes ao desenvolvimento do trabalho, mas na redução do sofrimento, que a segregação das relações interpessoais provocadas pela configuração do espaço pode provocar. (VILLAROUCO, 2004)

A Ergonomia do Ambiente Construído trabalha com a adaptação dos espaços para a necessidade e conforto dos usuários na utilização dos mesmos. É imprescindível que os arquitetos possam ter esse escopo ergonômico na realização dos projetos, para que se possa levar em consideração tanto aspectos de conforto e físicos quanto aspectos perceptivos e cognitivos.

Diante desse contexto de percepção ambiental podemos dizer ainda que para pessoas com deficiência auditiva esse aspecto se torna ainda mais relevante, visto que a falta da audição traz consigo a necessidade de uma atenção redobrada com a percepção visual dos acontecimentos no seu círculo de presença visual e nos aspectos de organização do espaço físico. Estes aspectos se fazem imprescindíveis tanto relacionado a sua própria segurança quanto a integração das mesmas com um mundo sonoro. Exemplo dessa necessidade se observa na reunião de pessoas surdas, onde primeiramente há a reorganização do mobiliário e um círculo de conversa, para uma visão clara dos participantes, o ajuste da iluminação para evitar cansaço visual e outras adaptações no espaço como aberturas, espelhos e etc., demonstrando então a importância sumária de se pensar o design e a acessibilidade também para esta realidade.

A NBR 9050 trata de aspectos relacionados a acessibilidade a edificações e espaços e equipamentos urbanos, porém dentro do que é tratado na norma, existe pouquíssima referência para a necessidade de acessibilidade do espaço para a pessoa com deficiência auditiva, o que demonstra uma carência de estudos sobre o tema no Brasil. Sob os aspectos de uma visão ergonômica global, MONT'ALVÃO traz que

Já não é mais aceitável estudar o ambiente considerando somente as variáveis físicas (como p.ex. temperatura ou ruído), sem considerar a questão de orientabilidade, de acessibilidade, do design de móveis, otimização gráfica ou projeto de iluminação. (MONT'ALVẪO, 2011)

Diante do exposto procurou-se fazer uma relação do tema com a importância do desenho universal no projeto, o uso de intervenções de ergonomia do ambiente construído no espaço e a metodologia do DeafSpace utilizada por BAUMAN (2010) na elaboração do prédio dos Dormitórios da Gallaudet University em Washington D.C.

\section{DESIGN UNIVERSAL E ACESSIBILIDADE}

Entende-se como acessibilidade do ambiente construído a possibilidade de se chegar a um lugar e participar de suas atividades de uma maneira independente, com um mínimo de conforto e entendendo e participando da organização e tarefas ali desenvolvidas de forma clara. Para isso é necessário que se considere quatro componentes: a informação ou compreensão do ambiente, podendo se situar ou se deslocar a partir de informações dadas 


\section{$\ddot{1}^{\text {eneac }}$}

a partir do próprio ambiente, o deslocamento, considerando o fluxo livre das áreas de circulação, tanto verticais quanto horizontais, o uso, através de participação em atividades e utilização de equipamentos e mobiliários e a comunicação, através da fácil interação dos usuários com o ambiente, integrando e incluindo as pessoas e a sociedade e pensada através de configurações espaciais de mobiliário e tecnologias.

Esses quatro componentes são inter-relacionados e estão diretamente ligados ao Desenho Universal, que propõe um espaço projetado para diferentes tipos de usuários para que independente das limitações que possam ter condições igualitárias no uso do espaço. Ele segue sete princípios que devem nortear todo o escopo do projeto: o uso equitativo, a flexibilidade de uso, o uso intuitivo, a informação perceptível, a tolerância ao erro, o baixo esforço físico, o tamanho e o espaço suficientes para o acesso e uso. Seguindo esses princípios cria-se uma autonomia do usuário independentemente de existirem restrições.

Para que isso ocorra, o ambiente deve ser integrador, com formas comuns de vida, aprendizagem e trabalho entre as pessoas deficientes e não deficientes, sem estigmatização ou segregação. Para isso é necessário que se possam identificar quais elementos dificultam ou impedem a percepção, circulação, compreensão ou apropriação dos espaços e atividades pelos usuários e quais obstáculos sociais e/ou psicológicos existem que impedem seu uso adequado.

\section{MÉTOdOS DE AVALIAÇÃo NO ASPECTO PROJETUAL E NO AMBIENTE CONSTRUÍDO}

Antes de tudo, entende-se que um projeto centrado no usuário leva em consideração todos os aspectos relacionados ao elemento humano que ali vai habitar. Observa-se que uma postura preventiva se relaciona diretamente a uma economia posterior corretiva e uma melhor adaptação do usuário ao espaço.

Para que se possa utilizar uma ação ergonômica no processo projetual deve-se levar em consideração os seguintes aspectos: o conforto ambiental, como a iluminação, a ventilação, o ruído, a temperatura interna, etc., a percepção ambiental dos que utilizarão o espaço, a adequabilidade dos revestimentos propostos de acordo com a função do espaço, os aspectos cognitivos dos usuários e os aspectos de realização do trabalho e seus dimensionamentos necessários.

Dentro deste contexto, percebem-se alguns fatores fundamentais que são observados nos ambientes inadequados. No processo de elaboração de aspectos relacionados ao conforto ambiental levam-se em consideração normas vigentes que estabelecem padrões mínimos relacionados a ruídos, vibrações, iluminação, etc. Porém esses valores mínimos devem ser avaliados com cuidado, porque em diversas situações eles se tornam inadequados. A iluminação indireta, por exemplo, mesmo diante do recomendado pode se fazer insuficiente para que haja uma perfeita interação das pessoas com deficiência auditiva, já que o aspecto visual se torna primordial para que haja uma compreensão necessária.

Os aspectos de percepção ambiental que não levam em consideração fatores experienciais e de sentimentos dos usuários têm uma grande chance de se tornar falho, visto que eles não podem ser mensurados através de normas ou códigos. Alguns usuários não se sentem confortáveis em ambientes em que haja uma grande exposição externa do interior, e outros não têm uma boa percepção de espaços muito fechados.

Os materiais de revestimento e acabamento devem levar em consideração que tipo de atividades aquele espaço vai desempenhar. Materiais com uma reverberação alta podem tornar o ambiente incômodo e dificultar a compreensão de usuários surdos que se utilizam de aparelhos auditivos e implante coclear. 


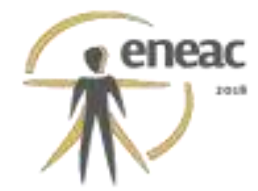

Os postos de trabalho que não avaliam as atividades que serão exercidas tendem a se tornar falhos devido a erros de dimensionamento. É necessário que se conheça que tipo de atividade será executada ali e como tornar o espaço funcional e confortável aos seus usuários e suas diversidades.

Em relação ao ambiente construído se faz necessário uma metodologia ergonômica específica, em que se leve em consideração tanto o ambiente físico quanto os aspectos de percepção ambiental.

No campo da percepção, mapas cognitivos ou mentais conseguem estabelecer traços comportamentais e preferências visuais, importantes influenciadores no conforto psicológico do espaço. Através deles se consegue identificar os usos, os arranjos espaciais ou layouts, os fluxos e as relações espaciais observadas.

Podemos utilizar para este fim o Método de Análise do Ambiente Construído, que a Constelação de Atributos. O primeiro método compreende quatro etapas: a análise global do ambiente, a identificação da configuração ambiental, a avaliação do ambiente em uso no desempenho das atividades e a análise da percepção do usuário, sendo as três primeiras relacionadas ao aspecto físico do ambiente e a última à percepção do usuário sobre o espaço utilizado.

A Constelação de Atributos se relaciona a uma técnica de extração da percepção do usuário sobre o seu ambiente através de imagens simbólicas geradas a partir de associações espontâneas de ideias do ambiente e representa as vivências individuais do usuário, e são expostas através de gráficos para que haja compreensão das necessidades dos usuários sobre o local.

\section{A METODOLOGIA DEAFSPACE}

O DeafSpace leva em consideração fundamentalmente a consciência da linguagem gestual e a conectividade visual entre as pessoas, além do sentimento de segurança e bem estar e a clareza da circulação e dos percursos. Leva-se em consideração também a geometria circular, a largura, a coletividade, a redução de "pontos cegos" e as transparências.

Essa metodologia segue especificamente cinco preceitos. O primeiro se refere ao alcance sensorial (figura 1), onde se leva em consideração a orientação espacial e a consciência das atividades que se desenvolvem no ambiente como forma de trazer sensação de bem estar e de segurança. Os surdos têm uma percepção visual que lhes conferem uma capacidade de leitura do ambiente através de características que por vezes não são percebidas pelos ouvintes, como movimento de sombras, vibrações e leitura de expressões faciais do outro. O espaço em "360 graus" facilita essa orientação e a mobilidade do usuário.

Figura 1 - diagrama do espaço visual da pessoa

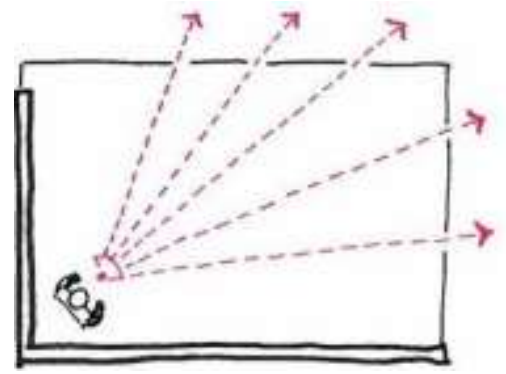

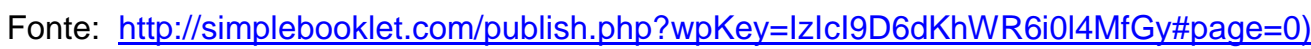




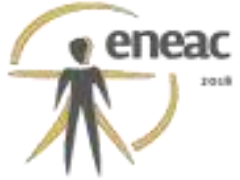

O segundo preceito trata do espaço e da mobilidade (figura 2), visto que para a pessoa surda é necessária uma distância específica para que se possa visualizar de forma clara tanto a expressão visual do outro como o seu entorno. O espaço entre dois surdos tende a ser maior que entre o espaço necessário em uma conversa falada. Sendo assim, o layout do mobiliário e as dimensões do espaço construído devem ter em conta esses fatores no processo projetual.

Figura 2 - espaço e mobilidade

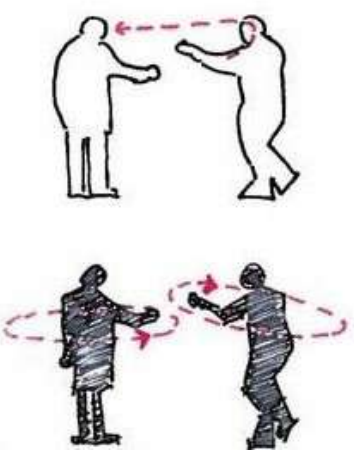

Fonte: http://simplebooklet.com/publish.php?wpKey=Izlc19D6dKhWR6i014MfGy\#page=0

O terceiro preceito se refere à mobilidade e a proximidade (figura 3), visto que para que haja uma comunicação visual existe a necessidade de uma distância do observador e capacidade de percepção do entorno e capacidade de percepção do perigo e da direção correta.

Figura 3 - mobilidade e proximidade

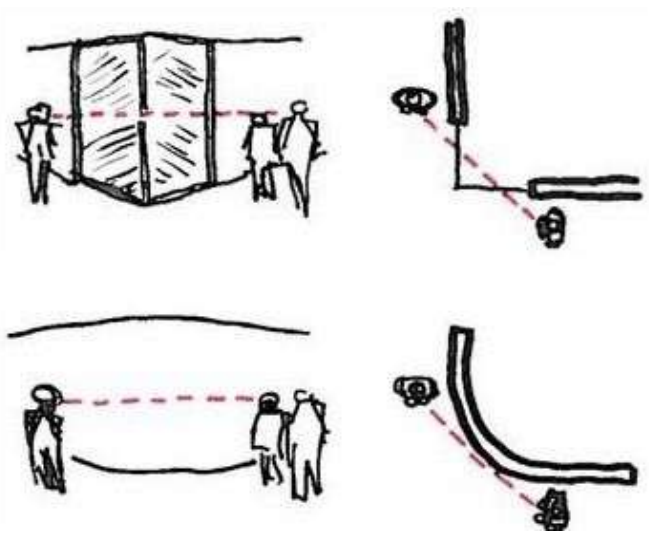

Fonte: http://simplebooklet.com/publish.php?wpKey=Izlcl9D6dKhWR6i014MfGy\#page=0

A luz e a cor (figura 4) são um preceito fundamental dentro dessa metodologia, visto que alguns aspectos de uma má iluminação interferem diretamente sobre a comunicação visual, como por exemplo brilho, padrões de sombra e luz de fundo que dificultam a interação e causa fadiga ocular. É imprescindível uma iluminação artificial adequada além de elementos arquitetônicos que controlem a luminosidade diurna para que haja sempre uma luz suave e difusa. As cores funcionam como elementos de contraste, além de ferramenta de estímulo ao conforto psicológico do local. 


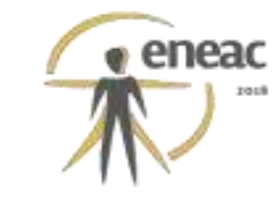

Figura 4 - luz e cor

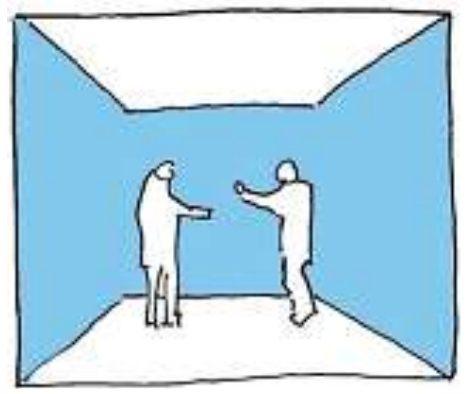

Fonte: http://simplebooklet.com/publish.php?wpKey=|z|cl9D6dKhWR6i014MfGy\#page $=0$

A acústica e as interferências eletromagnéticas (figura 5) têm uma influência direta sobre surdos usuários de prótese auditiva e de implante coclear, visto que o som pode ser um elemento de distração e de incômodo. Alguns elementos arquitetônicos e mobiliários rígidos aumentam a reverberação sonora e trazem desconforto. Todo o ambiente deve ser pensado levando em consideração a redução dos ruídos de fundo. Além disso, elementos de revestimentos que possam trazem isolamento acústico possibilitam aos surdos que estão em processo de reabilitação auditiva possam fazer uso de meios tecnológicos com mais conforto e compreensão, como por exemplo assistir televisão ou ouvir música.

\section{Figura 5 - acústica}

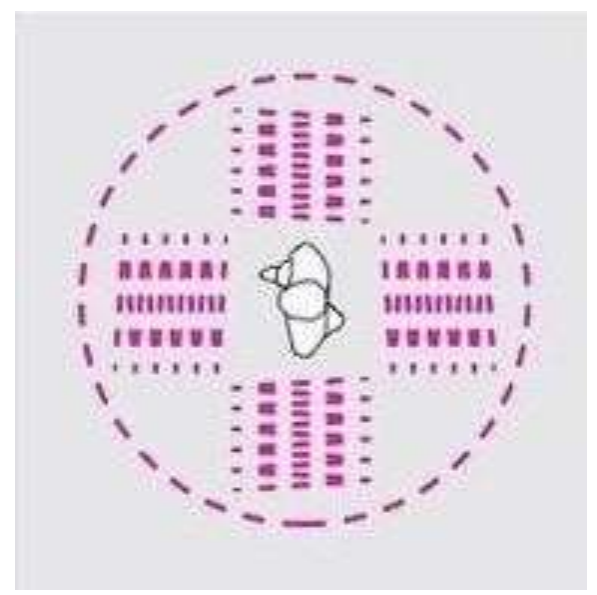

Fonte: https://archpaper.com/2015/10/architecture-gallaudet-university-set-design-urban-environmentdeaf/

Essas diretrizes são essenciais para o desenvolvimento de um ambiente que seja funcional e confortável a uma pessoa surda e traz assim, através de elementos simples a inclusão desse perfil no ambiente de forma positiva e acessível.

Os métodos de avaliação ergonômica do espaço construído podem e devem ser adaptados para que haja uma avaliação em um aspecto mais visual, através de imagens, associações e exemplos concretos, tendo assim chance maior de sucesso no seu propósito. 


\section{$\prod^{\text {eneac }}$}

\section{CONCLUSÃO}

Conclui-se então que é de fundamental importância que haja um método ergonômico no processo projetual para que o espaço possa ser confortável, estético e funcional. Também se observa que deve se levar em consideração a percepção visual do usuário, através de métodos de avaliação que escutem a pessoa usuária ou futura usuária do local, e que exista um conhecimento prévio das atividades que ali vão se desenvolver.

Em relação ao usuário surdo faz-se necessário um estudo mais profundo sobre a importância da conscientização das necessidades desse grupo social, para que também a eles cheguem espaços acessíveis e inclusivos.

\section{REFERÊNCIAS BIBLIOGRÁFICAS}

BAPTISTA, Mariana Bertani et al. E agora? Uma metodologia para discutir o desenho universal em projetos padronizados. Recife: VI Encontro Nacional de Ergonomia do Ambiente Construído, 2016. Disponível em: < http://www.proceedings.blucher.com.br/article- details/e-agora-uma-metodologiapara-discutir-o-desenho-universal-em-projetos- padronizados-22646>

CUNHA, Marcella Viana Portela de Oliveira; GOMES, Emmily Gersica Santos; FERNANDES, Júlio Cesar Felix de Alencar. A relação entre o ambiente e o usuário: o mapa comportamental como instrumento de definição de rota acessível. Disponível em:

http://www.proceedings.blucher.com.br/article-details/a-relao-entre-o-ambiente-e-o-usurio-o- mapacomportamental-como-instrumento-de-definio-de-rota-acessvel-22621

FRANSOLIN, Liorne Cristina et al. O jogo da arquitetura: discutindo a acessibilidade para surdos. Recife: VI Encontro Nacional de Ergonomia do Ambiente Construído, 2016. Disponível em: http://pdf.blucher.com.br.s3-sa-east-1.amazonaws.com/designproceedings/eneac2016/ACE06-4.pdf

RANGEL, Márcia Moreira; MONT'ALVÃO, Cláudia Renata. Arquitetos e designers: a concepção de projetos para os sistemas informacionais do ambiente construído e a participação do usuário. Joinville: 14 Congresso Internacional de Ergonomia e Usabilidade de Interfaces Humano-Tecnologia, Produto, Informações, Ambiente Construído e Transporte, 2014. Disponível em http://www.leui.dad.puc-rio.br/arquivosartigos/rangel montalvao ergodesignusihc2014.pdf

SOBRAL, Elzani Rafaela Ferreira de Almeida et al. Discussão acerca da percepção ambiental, suas ferramentas e cognição. Recife: 15 Ergodesign, 2015. Disponível em:

https://www.eed.emnuvens.com.br/design/article/view/278

VASCONCELOS, Christiane Falcão e; VILLAROUCO, Vilma; SOARES, Marcelo Marcio. Contribuição da psicologia ambiental na análise ergonômica do ambiente construído. Recife: Ação Ergonômica, vol.5. Disponível em: http://www.abergo.org.br/revista/index.php/ae/article/view/92

VILLAROUCO, Vilma. O que é um ambiente ergonomicamente adequado? São Paulo: I Conferência Latino-Americana de construção sustentável, 2004. Disponível em: ftp://ip20017719.eng.ufif.br/Public/AnaisEventosCientificos/ENTAC 2004/trabalhos/PAP007 0d.pdf 